\title{
Is exhaled nitric oxide a marker of air pollution effect?
}

\author{
Isabella Annesi-Maesano ${ }^{1}$ and Anh Tuan Dinh-Xuan ${ }^{2}$
}

\begin{abstract}
Affiliations: ${ }^{1}$ Epidemiology of Allergic and Respiratory Diseases Dept (EPAR), Sorbonne Universités, UPMC Univ Paris 06, INSERM, Pierre Louis Institute of Epidemiology and Public Health (IPLESP UMRS 1136), Saint-Antoine Medical School, Paris, France. ${ }^{2}$ Université Paris Descartes, Hôpital Cochin - Paris Centre, Assistance Publique Hôpitaux de Paris, Laboratoire de Physiologie Respiratoire, UPRES-EA 2511, Paris, France.
\end{abstract}

Correspondence: Isabella Annesi-Maesano, EPAR, Sorbonne Universités, UPMC Univ Paris 06, INSERM, Pierre Louis Institute of Epidemiology and Public Health (IPLESP UMRS 1136), Saint-Antoine Medical School, 27n rue Chaligny, F75012 Paris, France. E-mail: annesimaesanodgmail.com

O @ERSpublications

It is open to debate whether FeNO is a biomarker of the effects of air pollution http://ow.ly/ZrSke

Exhaled nitric oxide, measured through noninvasive breath testing with a portable device [1], is an established biomarker of airway inflammation [2]. This relies on the fact that $\mathrm{NO}$ is a gaseous molecule produced in a type of inflammatory response. Specifically, in humans, NO is produced from L-arginine, an $\alpha$-amino acid that is used in the biosynthesis of proteins, by three enzymes called NO synthases (NOS), namely inducible NOS (iNOS), endothelial NOS and neuronal NOS [3]. In the state of inflammation, several cells, including eosinophils, use iNOS to produce NO. Due to these properties, exhaled NO has been used as a biomarker for the diagnosis and follow-up of asthma, and as a guide to therapy in asthmatics $[4,5]$.

As air pollution is at the origin of inflammatory processes in the airways and in the lung, various studies investigated the relationship between measurement of the exhaled nitric oxide fraction $(\mathrm{FeNO})$ and air pollution. At the population level, elevated FeNO has been associated with both short-term [6] and long-term [7] exposure to air pollution, as objectively measured [7, 8] or on the basis of markers of traffic air pollution [9]. Exposure to air pollution may lead to airway inflammation, as measured by FeNO, even in children with no history of airway damage, and the association is enhanced in atopic subjects [8], which suggests a proper role for NO. Not only chemical agents but also biocontaminants were associated with FeNO. Early-life exposure to bacterial endotoxin and early-life dog ownership are associated with lower FeNO at school age [10]. Furthermore, mouse allergens in house dust was associated with an increased FeNO in the occupants [11]. However, at the individual level, acute daily changes in FeNO were not related to personal endotoxin exposure and there was limited evidence of effect modification of endotoxin by personal exposure to air pollution in that study [12]. At the experimental level, 2-h exposure to generated sulfate and soot particles was related to significant increases in FeNO in young and health subjects [13]. In children seen in two seasons, 24-h and weekly exposures to black carbon were linked with FeNO, while exposure on the morning of sampling was associated with airway oxidative stress [14], independently of sex, age, allergy status, parental education level and meteorological conditions on the sampling day.

The relationship between FeNO and air pollution may depend on individual susceptibility. In a large population, the promoter haplotypes in iNOS (NOS2) and exposure to residential traffic independently influenced $F$ eNO level [15]. Moreover, it was later found that higher exposure from residential traffic nullifies the protective effect of one common NOS2 promoter haplotype on FeNO. In children who had $\leqslant 250 \mathrm{~m}$ of local road length within a 100-m buffer around their homes, those with two copies of the haplotype had significantly lower FeNO than those with no copies, with statistically significant trend of lower FeNO with increasing number of haplotype copies [16]. In contrast, among children who had $>250 \mathrm{~m}$ of local road length within a $100-\mathrm{m}$ buffer, FeNO level did not significantly differ by the haplotype copy number [16].

Received: March 112016 | Accepted: March 112016

Conflict of interest: None declared.

Copyright OERS 2016 
Very recently, in an area of overall poor air quality from a major freight railway, male schoolchildren were a vulnerable subpopulation for more greatly elevated FeNO, while females were at increased risk of reduced lung capacity [17]. Noticeably, in spite of the fact that in polluted air, physical activity may increase air pollutant uptake and thereby health effects, no consistent evidence for an interaction between physical activity and traffic-related air pollution (TRAP) was observed for lung inflammation and systemic inflammation (interleukin-6, and leukocyte and neutrophil counts) [18].

In this issue of the European Respiratory Journal, EcKel et al. [19] show, for the first time, robust evidence for an association of TRAP exposure in the indoor microenvironment, as assessed by exhaled NO measured indoors [3], and elevated FeNO from distal sources among 1635 schoolchildren aged 12-15 years in southern California breathing NO-free air. Associations were less consistent with FeNO from proximal sources. The study by ECKEL et al. [19] is the first to have, using an adapted model [20], partitioned FeNO into proximal and distal, and thus to estimate in detail the NO parameters in the lower airways. In their work, indoor air pollution has been related to alveolar NO concentration, maximum airway wall NO flux and airway wall tissue diffusing capacity, which can be useful for understanding the underlying mechanisms. No such a detailed exploration of FeNO pathways had been conducted previously in a general population.

Whether exhaled NO can be considered a marker of air pollution exposure or effect has to be debated. A biomarker of exposure is a contaminant, its metabolite, or the product of interactions between the contaminant and some target molecule or cell measured in a compartment of the body reflecting internal or external exposure to the contaminant, whereas a biomarker of effect is a biological indicator of the body's response to exposure to a contaminant. The former has the ability to identify whether contamination has occurred as well as the route and pathway of exposure. The latter indicates early subclinical changes, which, if uninterrupted, may have pathological consequences and lead to specific diseases. Cumulating evidence supports the hypothesis that exhaled NO could be a marker of adverse effects of air pollution rather than a marker of exposure: the work of ECKEL et al. [19] has contributed additional elements supporting FeNO as a robust measure of the response of the respiratory system to air pollution exposure.

Nevertheless, several questions remain open and additional investigations are needed to evaluate whether exhaled NO satisfies the relevant criteria for being considered a biomarker of effect. Among others, as a biomarker of effect, FeNO should be reversible following avoidance of air pollution exposure, or at least reduced if an individual switches from elevated air pollution exposure to low exposure, and so far, controlled data are scarce in this respect. Furthermore, it is methodologically difficult to isolate the effect of air pollution from those of other stressors, like diet, infections or medications, in the lack of appropriate adjustment for confounders at the population level. Finally, yet importantly, analytical reproducibility, sensitivity, specificity and cost should be warranted in the case of FeNO as a biomarker of effect. This seems, however, to have been achieved through the official guidelines for FeNO [21]. Confirming the role of FeNO as a biomarker of effect will allow identification of the associated health end-points, and explore the opportunities of management and prevention.

Even if we still do not have all the evidence to specifically determine whether FeNO is a biomarker of the effect of air pollution, reducing air pollution can be worthwhile for airway and lung inflammation, and thus for respiratory health. In Beijing, China, in 2008, FeNO that was statistically associated with multiple pollutants across different lags after adjusting for meteorological parameters was significantly lower in the during that year's Olympic Games compared with before the games [22]. More recently, in the USA, adopting clean fuels and technologies on school buses showed to have reduced exposures and improved health schoolchildren [23]. Fine and ultrafine particle concentrations were $10-50 \%$ lower on buses using ultralow-sulfur diesel, diesel oxidation catalysts and/or closed crankcase ventilation systems. Ultralow-sulfur diesel adoption was also associated with reduced FeNO, greater growth in lung function and lower absenteeism, with stronger associations among asthmatic children. Finally, the findings of ECKEL et al. [19] draw our attention to the hazards of outdoor air pollution that can be found in the indoor microenvironment due to air transfer through windows. This indicates that prevention against poor air quality has to be extended to indoor settings where individual behaviour matters.

\section{References}

1 Harnan SE, Tappenden P, Essat M, et al. Measurement of exhaled nitric oxide concentration in asthma: NIOX MINO, NIOX VERO and NO breath. National Institute for Health and Care Excellence, Multiple Technology Appraisal process 2014. www.nice.org.uk/guidance/dg12. Date last accessed: March 10, 2016.

2 Dinh-Xuan AT, Annesi-Maesano I, Berger P, et al. Place de la mesure du NO expiré dans l'évaluation de l'inflammation bronchique dans l'asthme. Mise au point et position de la Société de pneumologie de langue française. [Contribution of exhaled nitric oxide measurement in airway inflammation assessment in asthma. A position paper from the French Speaking Respiratory Society.] Rev Mal Respir 2015; 32: 193-215.

3 Dinh-Xuan AT. Endothelial modulation of pulmonary vascular tone. Eur Respir J 1992; 5: 757-762.

4 Straub DA, Minocchieri S, Moeller A, et al. The effect of montelukast on exhaled nitric oxide and lung function in asthmatic children 2 to 5 years old. Chest 2005; 127: 509-514. 
Essat M, Harnan S, Gomersall T, et al. Fractional exhaled nitric oxide for the management of asthma in adults: a systematic review. Eur Respir J 2016; 47: 751-768.

6 Yoda Y, Otani N, Sakurai S, et al. Acute effects of summer air pollution on pulmonary function and airway inflammation in healthy young women. J Epidemiol 2014; 24: 312-320.

7 Berhane K, Zhang Y, Salam MT, et al. Longitudinal effects of air pollution on exhaled nitric oxide: the Children's Health Study. Occup Environ Med 2014; 71: 507-513.

8 Flamant-Hulin M, Caillaud D, Sacco P, et al. Air pollution and increased levels of fractional exhaled nitric oxide in children with no history of airway damage. J Toxicol Environ Health A 2010; 73: 272-283.

9 Eckel SP, Berhane K, Salam MT, et al. Residential traffic-related pollution exposures and exhaled nitric oxide in the children's health study. Environ Health Perspect 2011; 119: 1472-1477.

10 Casas L, Tischer C, Wouters IM, et al. Early life microbial exposure and fractional exhaled nitric oxide in school-age children: a prospective birth cohort study. Environ Health 2013; 12: 103.

11 Ahluwalia SK, Peng RD, Breysse PN, et al. Mouse allergen is the major allergen of public health relevance in Baltimore City. J Allergy Clin Immunol 2013; 132: 830-835.

12 Delfino RJ, Staimer N, Tjoa T, et al. Relations of exhaled nitric oxide and FEV1 to personal endotoxin exposure in schoolchildren with asthma. Occup Environ Med 2015; 72: 830-836.

13 Chen X, Sun Y, Han Y, et al. Design and characterization of human exposure to generated sulfate and soot particles in a pilot chamber study. J Air Waste Manag Assoc 2016; 66: 366-376.

14 De Prins S, Dons E, Van Poppel M, et al. Airway oxidative stress and inflammation markers in exhaled breath from children are linked with exposure to black carbon. Environ Int 2014; 73: 440-446.

15 Salam MT, Byun HM, Lurmann F, et al. Genetic and epigenetic variations in inducible nitric oxide synthase promoter, particulate pollution, and exhaled nitric oxide levels in children. J Allergy Clin Immunol 2012; 129: 232-239.e1.

16 Salam MT, Lin PC, Eckel SP, et al. Inducible nitric oxide synthase promoter haplotypes and residential traffic-related air pollution jointly influence exhaled nitric oxide level in children. PLoS One 2015; 10.

17 Spencer-Hwang R, Soret S, Ghamsary M, et al. Gender differences in respiratory health of school children exposed to rail yard-generated air pollution: the ENRRICH study. J Environ Health 2016; 78: 8-16.

18 Kubesch NJ, de Nazelle A, Westerdahl D, et al. Respiratory and inflammatory responses to short-term exposure to traffic-related air pollution with and without moderate physical activity. Occup Environ Med 2015; 72: $284-293$.

19 Eckel SP, Zhang Z, Habre R, et al. Traffic-related air pollution and alveolar nitric oxide in southern California children. Eur Respir J 2016; 47: 1348-1356.

20 Tsoukias NM, George SC. A two-compartment model of pulmonary nitric oxide exchange dynamics. $J$ Appl Physiol 1998; 85: 653-666.

21 Dweik RA, Boggs PB, Erzurum SC, et al. An official ATS clinical practice guideline: interpretation of exhaled nitric oxide levels (FENO) for clinical applications. Am J Respir Crit Care Med 2011; 184: 602-615.

22 Zhang J, Zhu $\mathrm{T}$, Kipen $\mathrm{H}$, et al. Cardiorespiratory biomarker responses in healthy young adults to drastic airquality changes surrounding the 2008 Beijing Olympics. Res Rep Health Eff Inst 2013; 5-174.

23 Adar SD, D'Souza J, Sheppard L, et al. Adopting Clean Fuels and Technologies on School Buses. Pollution and Health Impacts in Children. Am J Respir Crit Care Med 2015; 191: 1413-1421. 